\title{
Anterior Chamber Iris Claw Lens for the Treatment of Aphakia in a Patient with Megalocornea
}

\author{
Norman Saffra $^{a} \quad$ Aleksandr Rakhamimov $^{a} \quad$ Robert Masini $^{b}$ \\ Kenneth J. Rosenthal ${ }^{\mathrm{C}}$ \\ ${ }^{a}$ Department of Ophthalmology, Maimonides Medical Center, Brooklyn, N.Y., and \\ Departments of ${ }^{b}$ Medical Photography and ${ }^{c}$ Ophthalmology, New York Eye and Ear \\ Infirmary, New York, N.Y., USA
}

\section{Key Words}

Megalocornea $\cdot$ Aphakia $\cdot$ Iris claw lens

\begin{abstract}
Megalocornea in isolation is a rare congenital enlargement of the cornea greater than 13 $\mathrm{mm}$ in diameter. Patients with megalocornea are prone to cataract formation, crystalline lens subluxation, zonular deficiencies and dislocation of the posterior chamber intraocular lens (PCIOL) within the capsular bag. A 55-year-old male with megalocornea in isolation developed subluxation of the capsular bag and PCIOL. The PCIOL and capsular bag were explanted, and the patient was subsequently implanted with an anterior chamber iris claw lens. An anterior chamber iris claw lens is an effective option for the correction of aphakia in patients with megalocornea.

(c) 2015 S. Karger AG, Basel
\end{abstract}

\section{Case Presentation}

A 55-year-old male with megalocornea in isolation developed fluctuating visual loss in his right eye, exacerbated by head movements. His best-corrected visual acuity ranged from $20 / 40$ to $20 / 70$ depending upon the head position. A slit-lamp examination of the anterior segment demonstrated clear, compact corneas, with no scarring or deformity of Descemet's membrane. The corneas demonstrated increased horizontal and vertical diameters of 16 and $14 \mathrm{~mm}$, respectively, with keratometry readings of K1: $40.52 \times 169, \mathrm{~K} 2: 41.93 \times 79$. The anterior chambers were extremely deep (fig. 1) with iridodonesis and pseudophakodonesis. An 
Saffra et al.: Anterior Chamber Iris Claw Lens for the Treatment of Aphakia in a Patient with Megalocornea

abnormality of the posterior chamber intraocular lens (PCIOL) capsular bag complex was noted (fig. 2). An Axial length of $25.82 \mathrm{~mm}$ was measured by biometry. A funduscopic examination was within normal limits. An uneventful IOL (SN60WF 17.0D; Alcon Laboratories, Inc., Fort Worth, Tex., USA) and capsular bag explantation was performed, and the patient was left aphakic. A custom-manufactured aphakic contact lens was used for visual rehabilitation of the patient. He attained a visual acuity of 20/30. After 6 months, the patient developed severe contact lens intolerance, and a surgical option was sought.

Accordingly, the patient was enrolled in an FDA-monitored clinical trial (NCT01547429) for the ARTISAN aphakia lens for the correction of aphakia (secondary) in adults (Ophtec USA Inc., Boca Raton, Fla., USA). A 15.0 D lens was chosen based on IOL calculations utilizing the Holladay 2 formula. The artisan anterior chamber iris claw lens (ACICL) was implanted as follows: a biplanar $6.5 \mathrm{~mm}$ corneoscleral incision was performed. The pupil was constricted with acetylcholine chloride intraocular solution 1:100 to a diameter of approximately $3 \mathrm{~mm}$, and the anterior chamber was filled with viscoelastic. The ACICL was introduced through the incision, oriented in the horizontal plane, grasped with the inserter forceps (Artisan Enclavation Forceps, D02-40, Ophtec USA Inc.), and enclavated to the iris using an enclavation needle (Artisan Enclavation Needle, OD125, Ophtec USA Inc.). A previously made peripheral iridotomy was verified to be patent. The viscoelastic was irrigated from the eye and the incision was closed using 10-0 nylon sutures. The wound was Seidel tested and found to be negative (fig. 3; online suppl. video 1, see www. karger.com/doi/10.1159/000431251). Despite this, the postoperative course was complicated by a wound leak and hypotony due to a pathologically thin corneosclera. The patient was brought back to the operating room for a successful surgical wound revision.

At 10 months after surgery, the anterior chamber and Artisan lens remain in stable condition, without any evidence of intraocular inflammation. Manifest refraction, utilizing +0.75 $-1.00 \times 165^{\circ}$, yielded a best-corrected visual acuity of $20 / 30$.

\section{Discussion}

Megalocornea in isolation is a rare, congenital, bilateral condition that manifests itself via corneal enlargement of greater than $13 \mathrm{~mm}$ in diameter, with a normal histology and thickness. Males are more commonly affected as the hereditary patterns observed are either $\mathrm{x}$-linked or autosomal recessive. Megalocornea has been reported to coexist with other anterior segment abnormalities such as stromal mosaic dystrophy, arcus lipoides, iris anomalies including atrophy of the stroma, miosis, and microcoria (sometimes referred to as 'anterior megalophthalmos'] [1, 2]. It has also been associated with systemic diseases such as congenital Marfan syndrome, albinism, and Neuhauser syndrome [3].

The enlarged corneas are accompanied by an increase in the depth of the anterior segment and posteriorly positioned iris-lens diaphragm, resulting in a relatively shortened vitreous cavity [3]. Patients with megalocornea have a tendency to develop premature nuclear sclerotic cataracts [3]. The anomalous anatomy of the anterior chamber structures, predisposes patients to both crystalline lens subluxation [1] as well as to dislocate of the IOL within a pathologically large capsular bag [5].

Traditional methods of treating aphakia in patients with megalocornea involves fitting for aphakic spectacles, aphakic contact lens correction and alternate methods of IOL fixation. IOL calculations with first-generation lens formulas in these patients can be challenging as predicting the effective lens position may be difficult. The use of newer-generation formulas 
Saffra et al.: Anterior Chamber Iris Claw Lens for the Treatment of Aphakia in a Patient with Megalocornea

such as Holladay 2 [4] is therefore preferable to take into account, not only for the anterior chamber depth measurement, but also for the white-to-white measurements $[1,5]$.

Surgical options for correcting aphakia in these patients, utilizing currently available FDA-approved IOLs, is limited. Standard one-piece anterior chamber use is precluded in eyes with enlarged anterior segments as the haptic-to-haptic length of the largest model is 14.5 $\mathrm{mm}$ [6], which would preclude secure anterior chamber angle fixation. Patients with megalocornea are also not ideal candidates for the placement of a scleral fixated IOL since posterior chamber lenses are limited to $14.5 \mathrm{~mm}$ in their overall length [7] (14.0 $\mathrm{mm}$ in the United States). Both sutured as well as nonsutured externalized/intrascleral haptic techniques ('fibrin glued IOL') have been successfully reported for the scleral fixation of a posterior chamber lens within the posterior chamber [8]. Both of these techniques are very challenging in eyes with megalocornea due to the enlarged sulcus diameter. Many of the available 14.0-mm IOLs have flexible haptics that can be stretched further than $14.0 \mathrm{~mm}$ to potentially fill in the enlarged ciliary sulcus. However, there are concerns regarding the long-term stability of the haptics, as fixating the haptics when stretched beyond their intended dimension puts increased mechanical stress on the fixating sutures or fibrin glue. The stress on the sutures may induce early suture erosion or IOL displacement [9], thus causing lens instability and the possibility of haptic damage, with the late dislocation of the IOL. Furthermore, the IOLs haptics were designed to withstand compression within the capsular bag, and not stretching, which may cause biomechanical weakening of the haptics especially at the optic/haptic juncture compromising IOL stability.

Posterior iris fixation of the IOL is theoretically also a viable surgical option in the treatment of aphakia in these patients [10]. However, there are significant technical challenges to the use of the McCannel suture technique due to the enlarged anterior segment, small poorly dilating pupils [5] and 9-0 or 10-0 prolene sutures with needles of limited length.

Fixation of an IOL to the anterior surface of the iris has significant advantages in these patients. K.J.R. has proposed suturing of a conventional three-piece IOL directly to the anterior surface of the iris [11]. Anterior fixation of the IOL does not require an intervention behind the pupil, thus reducing the risk of a dropped IOL especially in vitrectomized eyes. This anterior iris approach of fixating the IOL allows for ease of an IOL exchange (in case it should be necessary). This approach is not without technical challenges as the limitations of needle length on the appropriate sutures exist.

ACICL allows the implantation in the absence of capsular support as its fixation does not depend on contact with the anterior chamber angle, ciliary sulcus, or sclera. The implantation within the anterior chamber and the enclavation to the iris stroma eliminates the need for any posterior or anterior suturing, making the procedure very efficient. In the event of a refractive surprise, which, as a result of the abnormal anatomic proportions in eyes with megalocornea, makes the exchange of the ACICL easy. This is in sharp contrast to performing an IOL exchange in a patient with either posterior iris or scleral fixation, where a removal can be at least as difficult if not more difficult than the primary procedure. Complications of IOL exchange carry the risk of iris damage or IOL luxation into the vitreous cavity. The longterm complications of artisan lens implantation include pupil ovalization, disenclavation, and subluxation.

Our case illustrates that the use of the artisan aphakia IOL is well suited for the treatment of aphakia in patients with megalocornea. The iris claw lens has been used in the past with success [12]. Its use in primary cataract surgery could be considered as well. 
Saffra et al.: Anterior Chamber Iris Claw Lens for the Treatment of Aphakia in a Patient with Megalocornea

\section{Statement of Ethics}

Informed consent has been obtained from the subject and the study protocol has been approved by the institute's committee on human research.

\section{Disclosure Statement}

Kenneth J. Rosenthal is a medical monitor for an Ophtec USA Inc., FDA clinical trial. He received noncash equivalents (e.g. devices at no cost) from Ophtec USA Inc.

\section{References}

1 de Sanctis U, Grignolo FM: Cataract extraction in X-linked megalocornea: a case report. Cornea 2004;23:533-535.

-2 Uçakhan 00, Kanpolat A, Yilmaz N: In vivo confocal microscopy of megalocornea with central mosaic dystrophy. Clin Experiment Ophthalmol 2005;33:102-105.

-3 Meire FM, Delleman JW: Biometry in X linked megalocornea: pathognomonic findings. Br J Ophthalmol 1994;78:781-785.

4 Holladay IOL Consultant User's Guide and Reference Manual. Houston, Holladay Lasik Institute, 1999.

-5 Assia EI, Segev F, Michaeli A: Cataract surgery in megalocornea Comparison of 2 surgical approaches in a single patient. J Cataract Refract Surg 2009;35:2042-2046.

6 Alcon IOL product catalog. http://www.alcon.com (accessed August 2014).

7 Kuznetsov S, Novikov S, Selifanov Y: New torsion haptic intraocular lens model and its experimental and clinical study (preliminary report). http://www.escrs.org/milan2012/programme/posterdetails.asp?id=13416 (accessed August 2014).

-8 Ohta T, Toshida H, Murakami A: Simplified and safe method of sutureless intrascleral posterior chamber intraocular lens fixation: Y-fixation technique. J Cataract Refract Surg 2014;40:2-7.

9 Welder J, Oetting TA: Megalocornea, EyeRounds.org. September 16, 2010. http://webeye.ophth.uiowa.edu/eyeforum/cases/121-megalocornea.htm (accessed August 2014).

10 Basti S, Koch DD: Secondary peripheral iris suture fixation of an acrylic IOL in megalocornea. J Cataract Refract Surg 2005;31:7.

11 Lori Baker Schena. Anteriorly Sutured PCIOLs May Overcome Weak Capsular Support. http://www.aao.org/publications/eyenet/200901/cataract.cfm.

-12 Oetting TA, Newsom TH: Bilateral Artisan lens for aphakia and megalocornea: long-term follow-up. J Cataract Refract Surg 2006;32:526-528. 
Saffra et al: Anterior Chamber Iris Claw Lens for the Treatment of Aphakia in a Patient with Megalocornea

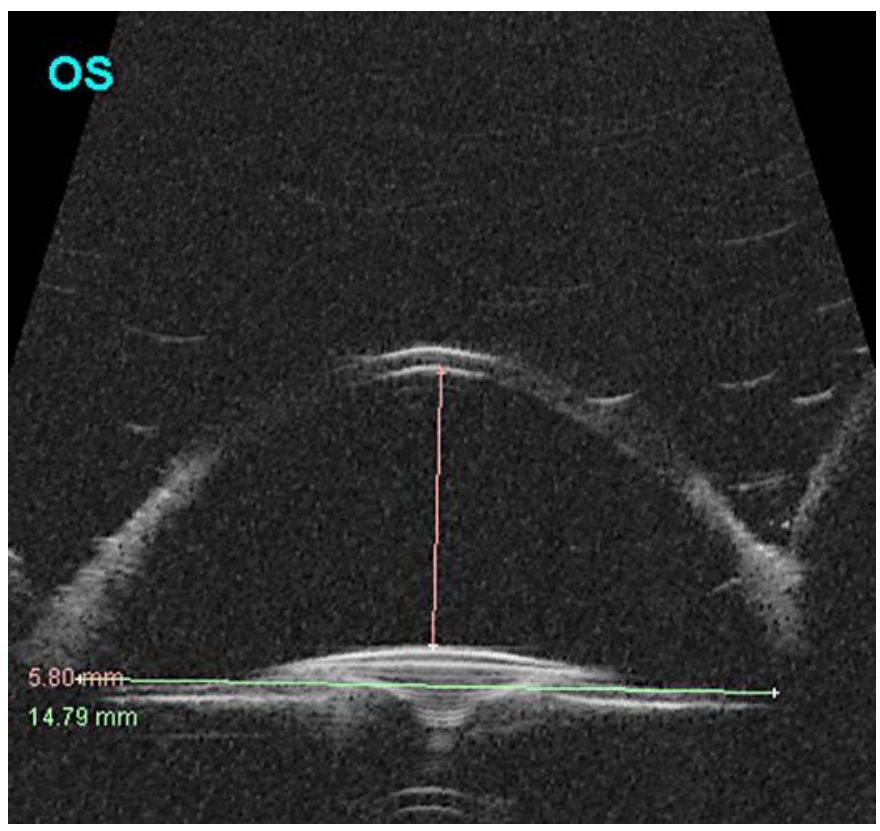

Fig. 1. An ultrasound biomicroscopy of the postoperative eye shows a clearance of $5.80 \mathrm{~mm}$ from the surface of the ICL to the cornea. The interangle-to-angle diameter is $14.79 \mathrm{~mm}$.

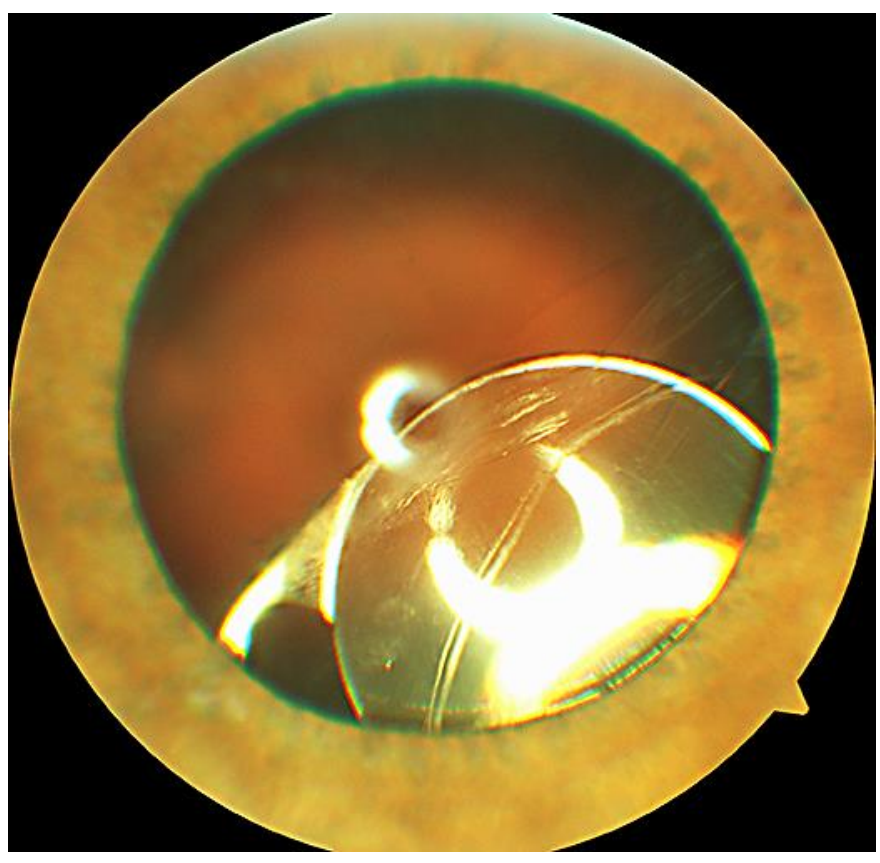

Fig. 2. Subluxating IOL within an enlarged capsular bag. 
Case Reports in

Ophthalmology

Saffra et al: Anterior Chamber Iris Claw Lens for the Treatment of Aphakia in a Patient with Megalocornea

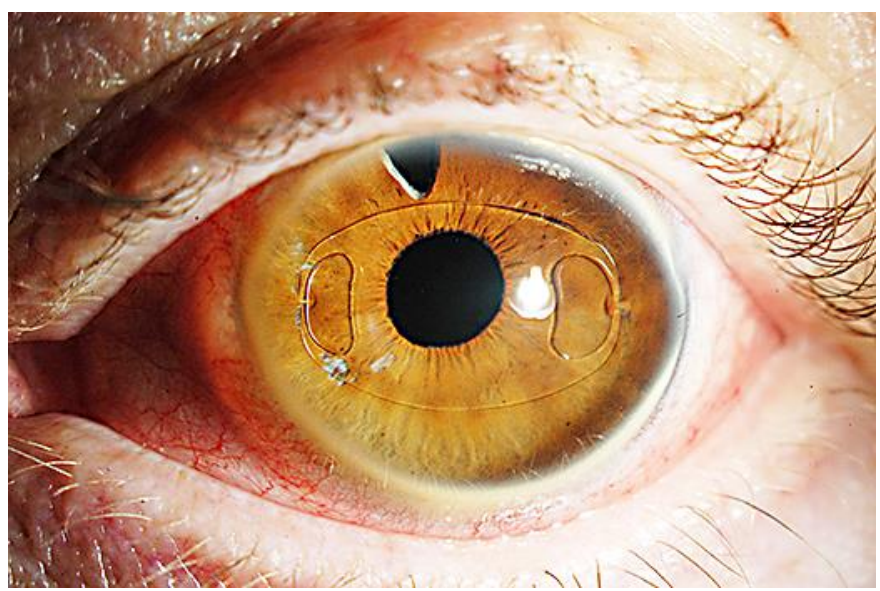

Fig. 3. Artisan ICL implanted with the haptics clipped to the iris. 